\title{
Kepribadiaan Konselor Dan Proses Konseling Melalui Pendekatan Kearifan Budaya Lokal Applekelebbireng Pada Masyarakat Bugis Bone
}

\author{
Nurmawati \\ Universitas Muhammadiyah Prof. Dr. Hamka Jakarta \\ i_nur15@yahoo.com
}

\begin{abstract}
Abstrak
Konselor profesional merupakan figur yang dapat menampilkan dirinya sebagai teladan. Di antara kompetensi konselor, yang paling penting adalah kualitas pribadi konselor karena konselor sebagai pribadi harus mampu menampilkan jati diri secara utuh, tepat, dan berarti, serta membangun hubungan interpersonal yang baik sehingga menjadi motor penggerak keberhasilan layanan. Pribadi konselor merupakan 'instrumen' yang menentukan hasil positif dalam proses konseling, sebab inti dari proses terapeutik dalam konseling yaitu hubungan yang dibangun antara konselor dan konseli, sehingga kualitas pribadi konselor merupakan hal yang esensial bagi konselor untuk mencapai tujuan dalam proses konseling. Proses konseling tidak terlepas dari etnis budaya salah-satunya adalah budaya masyarakat Bugis Bone mappakalebbi sesama manusia dengan mendahulukan nilai-nilai appekelebbireng lempu', macca, mappassalama', Siri'. Nilai-nilai inilah yang harus diterapkan dalam proses konseling Bugis Bone dengan melihat kepribadian konselor dengan bertutur kata, cara berprilaku (Mappatabe', Berdiri jika ada tamu yang berkunjung, posisi duduk dan tidak memanggil orang tua dengan namanya).
\end{abstract}

Kata Kunci: Pribadi Konselor, Konseling, Appakalebbireng.

\begin{abstract}
Professional counselors are figures who can present themselves as role models. Among the counselor's competencies, the most important is the personal qualities of the counselor because the counselor as a person must be able
\end{abstract}




\section{Kepribadiaan Konselor Dan Proses Konseling Melalui ...}

to show the whole, precise, and meaningful identity and build good interpersonal relationships so that becomes the driving force of service success. Personal counselors are the 'instruments' that determine positive outcomes in the counseling process, because the core of the therapeutic process in counseling is the relationship built between counselors and counselees, so the counselor's personal qualities is the essential thing for counselors to achieve goals in the counseling process. The process of counseling is inseparable from ethnic culture one is the culture of Bugis Bone community mappakalebbi of fellow human beings by prioritizing the values of appakalebbireng lempu', macca, mappassalama', Siri'. These values should be applied in the Bugis Bone counseling process by looking at the personality of the counselor by speaking, how to behave (Mappatabe', standing if there are guests visiting, sitting position and not calling parents by name).

Keywords: Personal Counselor, Counseling, Appakalebbireng.

\section{A. Pendahuluan}

Bimbingan dan konseling telah diakui sebagai profesi tersendiri. Dengan pengakuan ini, para konselor dituntut untuk semakin profesional dalam menjalankan tugas konseling. Konselor merupakan pengampu pelayanan ahli bimbingan dan konseling. Bimbingan dan Konseling sebagai sebuah profesi digambarkan dengan tampilnya konselor yang dapat memberikan ketenteraman, kenyaman dan harapan baru bagi konseli. Untuk menjadi seorang konselor professional haruslah menampilkan sikap hangat, empati, jujur, menghargai, menghormati dan yang paling penting dapat dipercaya (terjaga kerahasiaan konseli). Tiga isu sentral dalam mendiskusikan tentang kualitas pribadi konselor, yaitu : pengetahuan, keterampilan dan kepribadian. Dari ketiga hal tersebut kepribadian merupakan hal yang paling penting meskipun yang lain juga tak kalah pentingnya dan ketiga merupakan satu kesatuan yang tak dapat dipisahkan.

Kualitas pribadi konselor merupakan faktor yang sangat penting dalam konseling. Beberapa hasil penelitian menunjukkan bahwa kualitas pribadi konselor menjadi faktor penentu bagi 
pencapaian konseling yang efektif. Di antara kompetensi konselor, yang dirasa paling penting adalah kualitas pribadi konselor, karena konselor sebagai pribadi harus mampu menampilkan jati diri secara utuh, tepat, dan berarti, serta membangun hubungan antarpribadi yang unik dan harmonis, dinamis, persuasif, dan kreatif, sehingga menjadi motor penggerak keberhasilan layanan bimbingan dan konseling. Dalam hal ini 'alat' yang paling penting untuk dipakai dalam pekerjaan seorang konselor adalah dirinya sendiri sebagai pribadi (our self as a person).

Untuk dapat melaksanakan peranan profesional yang unik dan terciptanya layanan bimbingan dan konseling secara efektif, konselor harus memiliki kualitas pribadi. Tyler menyatakan: “...success in counseling depend more upon personal qualities than upon correct use of specified techniques". Pribadi konselor yang amat penting mendukung efektivitas perannya adalah pribadi yang altuistis (rela berkorban) untuk kepentingan konseli. Kepribadian konselor merupakan titik tumpu yang berfungsi sebagai penyeimbangan antara pengetahuan mengenai dinamika perilaku dan teraputik.

Manusia memiliki status sosial yang tinggi di banding dengan makhluk lain. Konteks memuliakan sesama manusia dalam berinteraksi menjadi hal yang sangat penting, dalam hal ini appakalebbireng pada masyarakat Bugis Bone. Masyarakat Bugis Bone menjunjung tinggi harkat dan martabat manusia, menghormati, dihormati, menghargai dan memuliakan sesama manusia, dikenal dengan faham mappakalebbi'. Seperti memuliakan orang tua, tamu dan tetangga.

Siapa yang ingin dihormati oleh orang lain, maka hormatilah manusia lainnya, siapa yang ingin dimuliakan maka muliakanlah manusia lainnya. Memuliakan sesama manusia diaplikasikan dalam appakalebbireng yang berlandaskan nilai sipakalebbi', sipakatau' dan sipakainge' (saling memuliakan, saling memanusiakan, dan saling mengingatkan). Nilai yang terkandung dalam appakalebbireng ini dijaga, dipertahankan dan dihidupkan dan menjadi sebuah spirit peradaban masyarakat Bone semakin berintegritas, dikenal, disegani, dihormati dan dimuliakan dalam menjalin hubungan (proses konseling) dalam budaya Bugis Bone. 


\section{Kepribadiaan Konselor Dan Proses Konseling Melalui ...}

Aktivitas bimbingan dan konseling, pada dasarnya merupakan interaksi timbal-balik yang dibangun dengan mengetahui budaya yang ada dan di dalamnya terjadi hubungan saling mempengaruhi antara konselor sebagai pihak yang membantu dan konseli sebagai pihak yang dibantu. Hanya saja, mengingat konselor diasumsikan sebagai pribadi yang akan membimbing konseli dalam mencapai tujuan tertentu, maka dalam relasi ini sangat dibutuhkan adanya kapasitas tertentu yang harus dimiliki oleh seorang konselor. Kapasitas tertentu inilah yang menentukan kualitas konselor. Konseling yang efektif adalah bergantung pada kualitas hubungan antara konseli dengan konselor. Pentingnya kualitas hubungan konselor dengan konseli ditunjukkan melalui kemampuan konselor dalam kongruensi (congruence), empati (empathy), perhatian secara positif tanpa syarat (unconditional positive regard), dan menghargai (respect) kepada konseli.

Budaya appakalebbireng dalam menjalin hubungan semakin lama akan hilang dilihat dari banyaknya masyarakat berpendidikan yang tidak mengaplikasikan, sehingga perlu ada perhatian khusus untuk kembali menghidupkan budaya dan tradisi appakalebbireng dalam menjalin hubungan sosial.

\section{B. Pembahasan}

\section{Pribadi Konselor dalam konseling}

Corey menjelaskan bahwa bagian terpenting dalam konseling adalah menjadi konselor yang efektif. Beberapa penelitian pakar konseling mengemukan bahwa keefektifan konselor banyak ditentukan oleh kualitas pribadinya. Kualitas pribadi konselor adalah kriteria yang menyangkut segala aspek kepribadian sangat penting dan menentukan keefektifan konselor jika dibandingkan dengan pendidikan dan latihan yang diperolehnya. Hasil penelitian yang dilakukan Truax \& Charkhuff, Waren, Virginia Satir membuktikan bahwa keefektifan konselor banyak ditentukan oleh kualitas pribadinya. Rogers mengatakan bahwa kepribadian konselor lebih daripada tehnik konseling itu sendiri. Menjadi konselor yang baik, yaitu konselor yang efektif, perlu mengenal diri sendiri, mengenal konseli, memahami maksud dan tujuan konseling, serta menguasai proses konseling. Membangun hubungan konseling (counseling 
relationship) sangat penting dan menentukan dalam melakukan konseling. Seorang konselor tidak dapat membangun hubungan konseling jika tidak mengenal diri maupun konseli, tidak memahami maksud dan tujuan konseling, serta tidak menguasai proses konseling.

Dalam konteks bimbingan dan konseling kualitas pribadi konselor dalam hal sikap dan perilaku sehari-hari akan menjadi modal utama dan pertama dalam menjalankan bimbingan dan konseling yang efektif. Hal itu terjadi karena hanya dengan kualitas pribadi yang tinggilah tujuan konseling akan tercapai, yang lainnya ditentukan oleh teknik yang digunakan. Hal ini menunjukkan bahwa betapa pentingnya kualitas pribadi yang harus dimiliki oleh konselor.

Cavanagh merekomendasikan 12 kualitas pribadi seorang konselor, yaitu ; 1) Pemahaman tentang diri sendiri; karakteristik yang ditunjukkan adalah menyadari kebutuhannya, menyadari perasaannya, menyadari faktor yang membuat kecemasan dalam konseling dan cara yang dilakukan untuk mengurangi kecemasan, dan menyadari akan kelebihan dan kekurangan diri. 2) Kompetensi, upaya mendapatkan kualitas secara fisik, intelektual, emosional, sosial dan kualitas moral yang harus dimiliki oleh konselor. 3) Keadaan psikologis konselor yang baik, konselor yang memiliki kesehatan psikologis yang baik memiliki karakteristik, mencapai kepuasan akan kebutuhannya, proses konseling tidak dipengaruhi oleh pengalaman masa lalu dan pengalaman pribadi di luar proses konseling yang tidak memilliki implikasi penting dalam konseling. 4) Dapat dipercaya, konselor dituntut untuk konsisten dalam ucapan dan perbuatan, memakai ungkapan verbal dan non verbal untuk menyatakan jaminan kerahasiaan, tidak pernah membuat seseorang menyesal telah membuka rahasianya. 5) Kejujuran, konseor bersifat terbuka, otentik dan penuh keihklasan. 6) Memiliki kekuatan untuk mengayomi klien, kemampuan untuk membuat klien merasa aman yang ditunjukkan dalam hal memiliki batasan yang kebekuan suasana, berbagi pengalaman emosional dan memungkinkan klien menjadi peduliberalasan dalam berpikir, dapat mengatakan sesuatu yang sulit dan membuat keputusan yang tidak populer, fleksibel dan menjaga jarak dengan klien (tidak terbawa emosi klien). 7) Kehangatan, merupakan pada dirinya sendiri. 8) Pendengar yang 


\section{Kepribadiaan Konselor Dan Proses Konseling Melalui ...}

aktif, ditunjukkan dengan sikap dapat komunikasi yang sering dilakukan secara non verbal, dengan tujuan untuk mencairkan berkomunikasi dengan orang di luar kalangannya sendiri, memberikan perlakukan kepada klien dengan cara yang dapat memunculkan respons yang berarti, dan berbagi tanggung jawab secara seimbang dengan klien. 9) Kesabaran, sikap sabar ditunjukkan dengan kemampuan konselor untuk bertoleransi pada keadaan yang ambigu, mampu berdampingan secara psikologis dengan klien, tidak merasa boros waktu, dan dapat menunda pertanyaan yang akan disampaikan pada sesi berikutnya. 10) Kepekaan, memiliki sensitivitas terhadap reaksi dirinya sendiri dalam proses konseling, dapat mengajukan pertanyaan yang "mengancam" klien secara arif dan peka terhadap hal-hal yang mudah tersentuh dalam dirinya. 11) Kebebasan, sikap konselor yang mampu membedakan antara manipulasi dan edukasi serta pemahaman perbedaan nilai kebebasan dan menghargai perbedaan. 12) Kesadaran menyeluruh, memiliki pandangan secara menyeluruh dalam hal menyadari dimensi kepribadian dan kompleksitas keterkaitannya, terbuka terhadap teori-teori perilaku.

Beberapa hal yang dapat mempengaruhi konselor berperilaku secara tepat terkait dengan perspektif nilai adalah ; 1) konselor memiliki kualitas pribadi yang positif, 2) kemampuan memahami isu-isu etis dalam konseling, 3) adanya kesadaran kultural dalam konteks multi budaya, 4) konselor dapat membangun kualitas hubungan konselor dan klien yang efektif, dan 5) konselor mampu memahami prinsip-prinsip keyakinan dan nilai dari perspektif klien.

Hal ini mengisyaratkan bahwa tugas konselor perlu mamahami konteks multi budaya dalam proses konseling salahsatunya Bugis Bone dengan budaya masyarakat sosial appekelebbireng dengan tujuan memuliakan diri sendiri dengan memuliakan orang lain, menghormati sesama, memberikan pelayanan terbaik sebagai bukti saling menghargai satu dengan yang lainnya. Memahami dan mengamalkan nilai appakalebbireng bisa terjadi jika dimulai dari diri sendiri (konselor), misalnya sebagai konselor mengintegrasikan nilai-nilai apakakalebbireng dengan menggunakan kata "puang" pada orang tua atau orang yang lebih tua, 
kesopaan bertutur seperti iyye', tabe' dan semacamnya. Pada bentuk perbuatan seperti mappatabe' yaitu dengan menundukkan kepala dengan menjulurkan tangan ke depan adalah budaya Bugis Bone dalam menjalin hubungan sosial.

\section{Nilai-nilai Appakalebbireng pada masyarakat Bugis Bone}

Appakalebbireng berasal dari kata mappakalebbi' yang merupakan bahasa Bugis, kata mappakalebbi' berasal dari kata lebbi' yang artinya mulia, alebbireng berarti kemuliaan atau kehormatan, mallebbi-lebbi' agak mulia atau terhormat, mappakalebbi' berarti memberi penghormatan, pappakalebbi' berarti penghormatan, mappakalebbi' berarti memuliakan, dan appakalebbireng berarti melakukan penghormatan kata kerjanya. Dalam kamus bahasa Inggris penghormatan berarti admiration, homage, pada kamus bahasa Indonesia penghormatan berasal dari kata hormat yang artinya menghargai, perbuatan yang menandakan rasa khidmat atau takzim, penghormatan adalah proses, cara, perbuatan menghormati; pemberian hormat. Berikut nilai yang terkandung di dalamnya berdasarkan kebudayaan Bugis:

\section{a. Lempu'}

Dalam bahasa Indonesia lempu' berarti jujur, jujur berarti lawan dari bengkok. Banyak kisah dalam sejarah tentang nasehat kejujuran, Suatu ketika Tociung, cendiekiawan Luwu' dimintai nasehatnya oleh sang maha raja tentang kejujuran, beliau menjawab:

\section{Eppa'I gauna lempue}

- Risalaie naddampeng

- Riparennuangie temmaceko

- Temmangoangngenngi Tania olona

- Tennaseng deceng rekko nassamarini pudecengi

Artinya:

\section{Empat perilakunya orang jujur}

- memaafkan orang yang berbuat salah kepadanya,

- dipercaya lalu tak curang,

- tidak mengakui yang bukan haknya,

- tidak mengatakan kebaikan jika hanya untuk dirinya sendiri.

Berlaku jujur membimbing pada kebaikan, dalam proses konseling sangat memperhatikan sikap jujur, terbuka karena menjadikan manusia terhormat di hadapan manusia lainnya. Jika 


\section{Kepribadiaan Konselor Dan Proses Konseling Melalui ...}

seseorang tidak berprilaku jujur maka secara adat setempat membuat dirinya terhina, karena mencoreng nilai yang sangat mulia.

\section{b. Macca}

Macca, berarti pintar, cerdik, cerdas, matanre nawa-nawa. Nilai mappakalebbi' itu macca nasaba' napakei amaccangenna pakalebbiki padanna rupa tau, nagaukengngi gau decenna nasaba' sitinaja maelo' mappideceng artinya pintar berarti mengamalkan nilai kebaikan yang ada pada dirinya, manusia Bugis Bone mengatahui bahwa bukti kecerdasannya adalah dengan berbuat baik kepada orang lain.

\section{c. Mappassalama'}

Mappasalama' artinya saling memberikan keselamatan atau saling menyelamatkan, baik dalam bentuk ucapan (doa') dan tindakan. Konsep kehomatan (mappakalebbi') berujung menyelamatkan. Orang baik itu diidentikan dengan tutur kata dan perilakunya, tidak menyakiti orang dengan lisan maupun tangannya.

\section{d. Siri'}

Siri' dikenal pada bahasa Indonesia adalah malu atau rasa malu, pada manuskrip lontarak tidak memiliki konsep yang baku. Siri' adalah pappaseng (petuah lisan) sebagaimana ungkapan:

- Abekekko raung siri artinya lilitkan daun sirih pada pinggangmu, maksudnya selalulah menyertakan siri' (malu) pada dirimu.

- Tanekko raung siri' riolo bolamu, mutaneng perring rimunri bolamu artinya tanamlah daun sirih di depan rumah dan tanamlah bambu di belakang rumahmu maksudnya siri adalah siri' (malu) dan perring adalah perri (kesulitan/hambatan).

- Siri' emmi riaseng tau artinya siri' yang dinamakan manusia, maksudnya orang yang tidak memiliki siri' adalah bukan manusia, melainkan boneka atau binatang.

- Siri' emmi rionroang ri lino artinya karena siri' maka kita hidup di dunia.

- Naia tau de'e siri'na, de' rilainna olokolo'e, artinya manusia yang tidak memiliki siri' tiada bedanya dengan binatang, manakala tidak memiliki siri', manusia hanya bisa dikatakan menyerupai manusia. 
- Siritaji nakitau artinya karena siri'lah kita dikatakan manusia.

3. Kepribadiaan konselor dalam konseling Applekelebbireng masyarakat Bugis Bone

\section{a. Cara bertutur}

- Mengucapkan kata puang kepada orang yang lebih tua, guru, om/tante.

- Mengucapkan kata tabe' ketika ingin lewat.

- Mengucapkan kata iyye' ketika berdialog.

- Menucapkan idi' menunjukkan kita.

Dalam proses konseling seorang konselor harus benar-benar menjunjung tinggi nilai-nilai kesopanan dalam bertutur kata karena dengan bertutur kata yang baik proses konseling akan berjalan efektif dengan memuliakan, menghormati konseli melalui lisan. Tutur kata dan tindakan guru pembimbing selalu mengenakkan hati, hangat dan suka menolong.

\section{b. Cara berprilaku}

\section{1) Mappatabe'}

Mappatabe' itu tunduk berjalan di depan orang lain dengan menengadahkan tangan kedepan, seperti berjalan di depan umum atau berjalan di depan orang yang lebih tua. Mappatabe' adalah tunduk namun tidak menyembah, praktek yang sangat sopan bagi seorang anak/konselor berjalan didepan atau dibelakang orang tua, berjalan di depan atau di belakang guru, berjalan di kerumunan orang banyak, dan di hadapan orang yang lebih tua atau lebih muda. Masyarakat Bugis Bone dikala memahami gerak-gerik mappatabe' maka melahirkan keharmonisan dalam bergaul dan proses pemberian layanan konseling.

Tradisi masyarakat Bugis Bone pada konsep appakalebbireng adalah bagaimana bersikap menghargai dengan gerakannya, dikenal dengan istilah mappatabe (minta izin), seorang anak yang lebih muda berjalan dikerumunan orang yang lebih tua maka harus memohon izin dengan dengan dibuktikan dengan tindakan. Memuliakan orang merupakan kearifan lokal pada masyarakat Bugis Bone, baik dilihat dari sisi agama Islam, budaya lokal dan dalam praktek konseling. Mappakalebbi' merupakan budaya lokal yang harus dilestarikan, agar muncul perbuatan yang menunjukkan bahwa masyarakat Bugis Bone faham budayanya dan mengamalkan agamanya (agama Islam). 


\section{Kepribadiaan Konselor Dan Proses Konseling Melalui ...}

Perilaku mappakalebbi' menghidupkan budaya lokal sehingga masyarakat mampu memilih dan memilah berbagai budaya dari luar. Konselor harus Ramah, penuh perihal, dan memberikan kasih sayang. Klien yang datang meminta bantuan konselor pada umumnya yang kurang mengalami kehangatan dalam hidupnya, sehingga klien kehilangan kemampuanya pada lingkungan sekelilingnya. Maka melalui proses konseling, klien ingin mendapatkan rasa hangat tersebut melalui sharing dengan konselor.

\section{2) Berdiri jika ada tamu yang berkunjung}

Proses konseling jika konseli datang kepada konselor maka konselor wajib berdiri dan menghampiri konseli. Jika ada tamu yang datang semua pihak tuan rumah wajib berdiri untuk menyambut tamu yang datang. Begitupula jika tamu tersebut kembali maka dari pihak tuan rumah juga berdiri sebagai bukti penghormatan kepada tamu. Masyarakat memberikan pelayanan sangat berbeda antara raja, bangsawan dan masyarakat biasa, perlakuan tersebut merupakan tradisi turun temurun di Bugis Bone, namun seiring denga perkembangan zaman, banyak tradisi yang berubah dan tidak sesuai dengan masa dahulu, pelayanan kepada tamu tidak lagi dibedakan antara raja, bangsawan dan masyarakat biasa, tetangga jauh dan tetangga dekat, semua mendapatkan pelayanan yang sama, dan mendapatkan perlakuan yang sama, semua sama-sama dihormati dan dilayani.

Menurut Carkhuff menyebutkan bahwa attending adalah cara yang menunjukan bagaimana konselor menyiapkan diri, bersikap atau berperilaku, mendengarkan, memberikan perhatian kepada konseli sehingga konseli merasa aman, nyaman, diperhatikan oleh konselor.

Dengan kata lain attending adalah ketrampilan/teknik yang digunakan konselor untuk memusatkan perhatian kepada klien agar klien merasa dihargai dan merasa dibimbing dengan suasana yang kondusif sehingga klien bebas mengekspresikan / mengungkapkan pikiran, perasaan ataupun tingkah lakunya.Perilaku attending dapat juga dikatakan sebagai penampilan konselor yang menampakkan komponen-komponen perilaku nonverbal, bahasa lisan dan kontak mata. 


\section{3) Posisi duduk}

Tradisi kerajaan berbeda dengan masyarakat biasa, jika masyarakat biasa berkunjung kerumah sang raja, posisi duduknya harus dibawah dan masyarakat biasa duduk dibawah sebagai bukti penghormatannya. Ketika sang raja berkunjung ke kerumah rakyatnya, maka harus menyiapkan kursi kemudian duduk dibawah. Ketika memposisikan orang tua, maka Dipaddiolo to matoae tudang narekko engka tudangeng (mendahulukan orang tua duduk jika ada kursi), dengan memberikan posisi duduk kapada yang lebih tua, baik di rumah, di bus, di tempat antrian, itu membuktikan penghormatan kepadanya.

Posisi badan (termasuk gerak isyarat dan ekspresi muka) diantara posisi badan yang baik dalam attending mencakup : a) Duduk dengan badan menghadap konseli. Tangan diatas pangkuan atau berpegang bebas atau kadang-kadang di gunakan untuk menunjukan gerak isyarat yang sedang dikomunikasikan secara verbal. b) Responsif dengan menggunakan bagian wajah, misalnya senyum spontan atau anggukan kepala sebagai persetujuan atau pemahaman dan kerutan dahi tanda tidak mengerti, c) Badan tegak lurus tanpa kaku dan sesekali condong kearah konseli untuk Menunjukan kebersamaan dengan konseli, d) d. Tidak memanggil orang tua dengan namanya. Nama adalah doa, namun anak memanggil orang tuanya secara etika dinila tidak sopan pada masyarakat Bugis Bone. Agama Islam mengajarkan manusia agar berakhlakul karimah, jika budaya Bugis menilai bahwa memanggil nama orang itu tidak sopan, maka dalam konseling hal itu dinilai tidak berakhlak dengan baik. Orang tua harus dimuliakan, salah satu cara memuliakannya itu dengan memanggilnya dengan tidak menyebut namanya namun sebutan puang.

\section{Simpulan}

Memperhatikan penjelasan di atas dapat kita pahami bahwa Indonesia merupakan bangsa multi etnis dan multi budaya. Proses konseling yang merupakan sentral layanan konseling dilakukan sesuai dengan kaidah profesi dan kode etik yang ditetapkan. 


\section{Kepribadiaan Konselor Dan Proses Konseling Melalui ...}

Konselor merupakan sebuah profesi, tuntutan secara profesi, konselor harus memiliki kualitas pribadi yang memadai untuk menunjukkan profesionalisme perilaku dan aktivitasnya. Konselor yang memiliki pribadi mantap, akan sangat menyadari profesinya.

Kepribadiaan konselor yang mantap tentu memahami etnis pada pelaksanaan konseling, korelasi appakalebbireng pada tradisi masyarakat Bugis Bone bagaimana seorang konselor memuliakan dan menghormati sesuai adat istiadat, pemahaman, kebiasaan yang dilakukan pada masyarakat Bugis Bone sipakalebbi sipakatau lao ri padanna rupa tau (saling menghormati, memuliakan kepada sesama manusia) yang disesuaikan nilai appekelebbireng masyarakat Bugis Bone. 


\section{DAFTAR PUSTAKA}

Badudu. J. S dan Zain. 1996. Sutan Muhammad, Kamus Umum Bahasa Indonesia, Cet.III; Jakarta: Pustaka Sinar Harapan.

Corey, G. 1986. Konseling dan Psikoterapi. Jakarta : Alfabeta

Corey, Gerald. 2005. Theory and Practice of Counseling and Psychotherapy. Seventh Edition. Belmont : Brooks/Cole Thompson Learning.

Geldard, D, dan Geldard, K,. 2001. Basic Personal Counselling : Training Manual forCounsellors. Australia : Peardon Education, Inc.

Okun, Barbara F,. 2002. Effective Helping : Interviewing and Counseling Techniques. Canada. Wadsworth Group.

Pelras. Christian. 2005. Manusia Bugis judul Asli The Bugis, Cet. I; Jakarta: Efeo.

Said. Ide. 1997. Bugis Indonesia, Cet.I; Jakarta: Pusat Pembinaan dan Pengembangan Bahasa Depertemen Pendidikan dan Kebudayaan.

Tyler, L. E. 1969. The Work Of The Counselor. New York. Appleton Century Crofts, Inc.

Willis, Sofyan S. 2007. Konseling Individual Teori dan Praktek. Bandung: Alfabeta. 